Bangladesh J. Pl. Breed. Genet., 20(2) : 11-16, 2007

\title{
EVALUATION OF TRANSGENIC INDICA RICE (Oryza sativa L.) THROUGH REPORTER AND DESIRED GENE
}

\author{
Shamsul H. Prodhan, K. Nagamiya, A. Komamine ${ }^{1}$, H. Morishima ${ }^{2}$ \\ Laboratory of Plant Genetic Engineering, Institute of Life and Environmental Sciences, \\ University of Tsukuba, 1-1-1Tennodai, Tsukuba city, \\ Ibaraki 305-8577, Japan.
}

\begin{abstract}
Rice is one of the most important food crops in the world. It is greatly affected by various abiotic stresses. Among them, to improve the complex stress salinity we introduced a desired gene katE, a catalase gene of Escherichia coli, and reporter gene GUS into the indica rice cultivar Kasalath. Plant survival under different salt water concentration was checked. Transformation was carried out using Agrobacterium tumefaciens strain EHA101 harboring a binary vector $\mathrm{pIES6/Hm} / \mathrm{katE}$ and $\mathrm{pIG121/}$ $\mathrm{Hm} /$ GUS which contains genes for catalase katE, GUS gene, hygromycine resistance gene HPT and kanamycine resistance gene NPTII in the T-DNA region. Transformation was confirmed by PCR with katE and GUS primer. Transgenic plants at very young stage ( 3 days) were able to grow up to 15 days in $100 \mathrm{mM} \mathrm{NaCl}$ solution and 7 days in $250 \mathrm{mM} \mathrm{NaCl}$ solution where as non transgenic plants could not survive even up top 5 days in $100 \mathrm{mM}$ condition and 7 days in $250 \mathrm{mM} \mathrm{NaCl}$ concentration. Twenty eight days matured plants could survive and were able to form iflorescence. Here a single gene introduction significantly improved the salt tolerance of this crop rice.
\end{abstract}

Key words: Rice (Oryza sativa L), Agrobacterium tumefaciens, transformation, reporter gene, acetosyringon, binary vector.

\section{INTRODUCTION}

Rice productivity is greatly affected by a complex trait salt stress. This is regulated by various mechanisms. Organisms that thrive in hyper saline environments possess different mechanisms to adjust internal osmotic status. One of the such mechanisms is the ability to accumulate low molecular organic compatible solutes such as sugars, some amino acids and quaternary ammonium compounds, which are believed to be essential for adaptability of plant cells to high salinity (Bohnert et al., 1995).

The mechanisms of adaptation to salt stress are the exclusion of $\mathrm{Na}$ cations from the sodium sensitive sites which has been proposed as a function $\mathrm{a} \mathrm{Na}^{+} / \mathrm{H}^{+}$antiporter and $\mathrm{Na}^{+}$ATPase (Serrano, 1996). Salt loading also induces oxidative stress. Upon salt stress, the $\mathrm{CO}_{2}$ fixation rate may be decreased causing the over reduction of the photosynthetic electron transport chain and the production of active oxygen species such as singlet

\footnotetext{
${ }^{1}$ The Research Institute of Evolutionary Biology. 2-4-28, Kamiyoga, Setagaya-ku,Tokyo, 1580098, Japan. ${ }^{2}$ Laboratory of Genetics and Plant Breeding, Department of Agricultural Science, Tokyo University of Agriculture, Japan
} 
oxygen $\left({ }^{1} \mathrm{O}_{2}{ }^{*}\right)$, super oxide anion $\left(\mathrm{O}_{2}-\right)$, hydrogen peroxide $\left(\mathrm{H}_{2} \mathrm{O}_{2}\right)$ and hyhdroxyl radical $(\mathrm{OH}) . \mathrm{H}_{2} \mathrm{O}_{2}$ is the most stable active oxygen species, but produces the most reactive oxygen species, $\mathrm{OH}$, if $\mathrm{H}_{2} \mathrm{O}_{2}$ is present together with $\mathrm{O}_{2}$ - and $\mathrm{Fe}^{2+}$.

The best documented source of $\mathrm{H}_{2} \mathrm{O}_{2}$ in photosynthetic organisms is $\mathrm{O}_{2}$ - generated by Mehler reaction. Therefore, the decomposition of $\mathrm{H}_{2} \mathrm{O}_{2}$ is most pivotal in the protection of the cells from oxidative damage. Early report of the effect of overexpression of the catalase gene on the oxidative stress as well as on the salt stress in cyanobacteria indicated that, the quenching of $\mathrm{H}_{2} \mathrm{O}_{2}$ was an important factor for salt tolerance (Kaku et al., 2000). Catalase is an antioxidant enzyme which has the more stable and difficult to denature character than the other antioxidants like ascorbate peroxidase. Normally catalase is expressed in microbody, mitochondria and chloroplast but not in the cytosol. Catalase breaks down hydrogen peroxide and produces $\mathrm{H}_{2} \mathrm{O}$ and usually $\mathrm{O}_{2}$ which helps for the survival of the plants.

The present research was conducted, to transform recalcitrant indica variety (Kasalath) with a gene encoding catalase, katE, derived from E. coli which decomposes $\mathrm{H}_{2} \mathrm{O}_{2}$ (Kaku et al., 2000) and reporter gene GUS. Salt tolerance of transgenic plants in different growth stages between transgenic and nontransgenic plants were investigated.

\section{Material and Methods}

\section{Plant material and bacterial strain}

Indica rice (Oryza sativa L) Kasalath was used for the present study and mature seed was used as explant. Transformation was conducted by using Agrobacterium

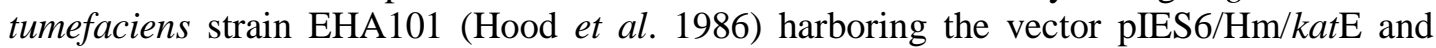
pIG121/Hm/GUS. Binary vector contains genes for catalase katE, GUS gene, hygromycine resistance gene HPT and kanamycine resistance gene NPTII in the T-DNA region. This Agrobacterium strain was provided from Dr. Elizabeth E. Hood of Washington University and katE gene was provided by Dr. Tetsuko Takabe of Nagoya University, Japan. The vector posses an enhancer region from CaMV promoter and connected to the $35 \mathrm{~S}$ promoter of cauliflower mosaic virus, there by helping for expression (Fig. 1 a \& b).

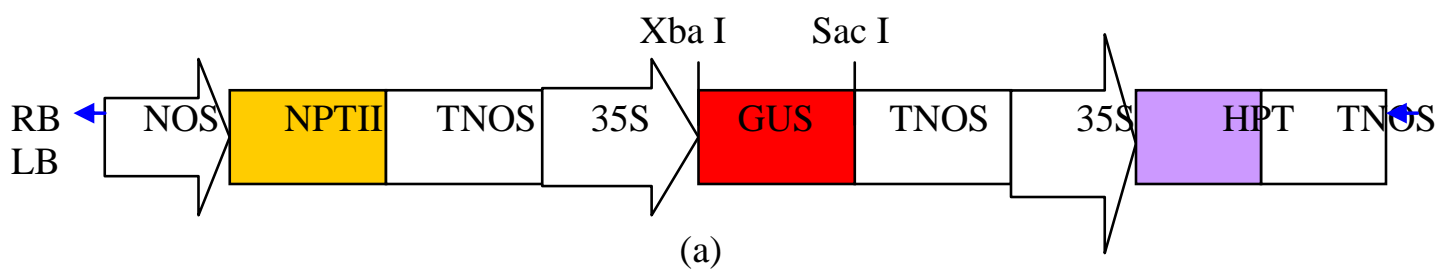

XbaI HindIII HindIII Sac I

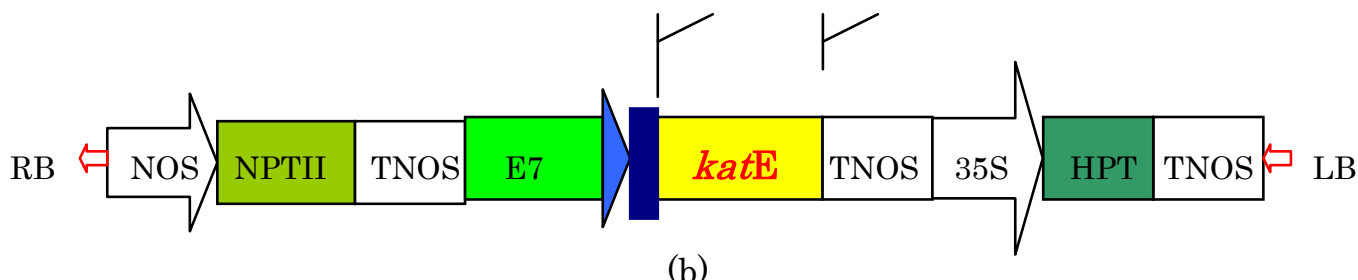

(b)

Fig.1. Schematic diagram of the constructed vector 


\section{Ttransformation and culture condition}

Rice transformation was conducted using the established methods of Hiei et al (1994) and Toki (1997). Callus was induced from indica rice (Oryza sativa L) seeds using N6 medium supplemented with $2 \mathrm{mg} / 1$ 2,4-D. Two weeks later induced calli, were infected with Agrobacterium tumefaciens EHA101 carrying $\mathrm{pIG} 121 / \mathrm{Hm} / \mathrm{kat \textrm {E }}$ and $\mathrm{pIG} 121 /$ $\mathrm{Hm} / \mathrm{GUS}$.

After three days of co culture, callus was sterilized with $500 \mathrm{mg} / \mathrm{l}$ carbenicillin and transferred to N6 selection medium containing $50 \mathrm{mg} / \mathrm{l}$ hygromycin and $500 \mathrm{mg} / \mathrm{l}$ carbenicillin for two weeks. Selected, calli were transferred to MS hormone free medium for regeneration. Regenerated plantlets were acclimatized in pots $(15 \mathrm{~cm}$ diameter $)$ with soil and submerged with water in a growth incubator at $30^{\circ} \mathrm{C}$ (light phase) and $25^{\circ} \mathrm{C}$ (dark phase) with 12 hours light at $71 \mathrm{~m}^{2}$ mole $\mathrm{m}^{-2} \mathrm{~s}^{-1}$ photon flux density and $62 \%$ relative humidity. Progenies were obtained from those transgenic plants by selfing under the same condition as mentioned above.

\section{PCR analysis}

Genomic DNA was extracted from young leaf tissues of $\mathrm{T}_{0}$ transgenic and non transgenic control plants. PCR was performed in a reaction mixture containing about $25 \mathrm{ng}$ plant genomic DNA, $100 \mu$ mole dNTP, $0.2 \mu$ mole of each primer and $1 \mathrm{U}$ of Taq polymerase (Takara, Japan). PCR analysis was carried out under standard condition with 30 second denaturation, 40 second annealing, 50 second extension at $94^{\circ} \mathrm{C}, 50^{\circ} \mathrm{C}$ and $72^{\circ} \mathrm{C}$ respectively, for 30 cycles. The sequence of the PCR primers for katE gene were as

follows: $1165 \mathrm{U}$ (CCACCAAgTTCTATACCgAAgAgg) and $1165 \mathrm{~L}$ (gTgATATTCAgCTggTCgTCAgTC) and for GUS gene was GUS-4 (AGGCTGTAGCCGACGATG) and GUS-F (ATCACCGAATACGGCGTGGA).

\section{Observation of salt tolerance}

Transgenic and non transgenic plants at different stages were used to evaluate the salt tolerance. One was at very young stage (3 days after root formation) another was 4 weeks after root formation. After acclimatization, $\mathrm{T}_{0}$ transgenic plants and wild plants were soaked in $0 \mathrm{mM}, 50 \mathrm{mM}, 100 \mathrm{mM}, 150 \mathrm{mM}, 200 \mathrm{mM}, 250 \mathrm{mM}$ and $300 \mathrm{mM}$ (half of the sea water level) concentrations of sodium chloride solution. For each sodium chloride concentration, at least two plants were used.

\section{RESULTS AND DISCUSSION}

We could transform recalcitrant Indica rice cultivar Kasalath with the katE gene that was derived from E. coli and designed to be expressed under the control of the 35S RNA promoter of the cauliflower mosaic virus with E7 enhancer and with GUS gene.

In Kasalath transformation with the vector pIES6katE and pIG121/ Hm/GUS were successful where $\mathrm{T}_{0}$ transformants and their progeny were investigated. We infected the calli with binary vector which were derived from a most common binary vector, pBI121 (Ohta et al., 1990). Rashid et al. (1996) used the same vector to obtain transgenic Basmati rice. In some reports, a super binary vector, in which a DNA fragment from the virulence region was introduced in to a binary vector, was more effective and easy for transformation of rice and they also described that recalcitrant cultivars can more easily be transformed by using the super binary vector (Hiei et al., 1994). Hashizume et al. 1999, 
also obtained high transformation frequencies even using conventional binary vector. In this study also conventional binary vector was used to obtain higher transformed recalcitrant Indica rice cultivars.

\section{Transformation efficiency}

Transformation frequency was $82 \%$ with the vector $\mathrm{pIG} 121 / \mathrm{Hm} / \mathrm{Gus}$ and $80 \%$ with the vector $\mathrm{pIES} 6 / \mathrm{katE} / \mathrm{Hm}$ at $100 \mu \mathrm{M}$ acetosyringone concentration. This report shows that, transgenic plants carrying katE gene were obtained with high efficiency. These values are as high as some Japonica cultivars (Hiei et al. 1994) and Indica cultivar Basmati 370 (Rashid et al. 1996). One of the most commonly used techniques in transformation of monocotyledonous plant is the addition of phenolic compound acetosyringon (Van Wordragen et al. 1992). According to James et al. 1993, acetosyringon treatment has been reported to be highly effective for increased transformation. Vijayachandra et al. 1995 reported that, rice tissues could induce expression of vir genes but that induction was greatly enhanced by acetosyringon. In this experiment also addition of higher concentration of acetosyringon $(100 \mu \mathrm{M})$ showed better result both in transformation and regeneration than $50 \mu \mathrm{M}$ concentration. This result shows similarity with Hiei et al. 1994, where they demonstrated that, acetosyringon at $100 \mu \mathrm{M}$ is a key factor for successful transformation of rice.
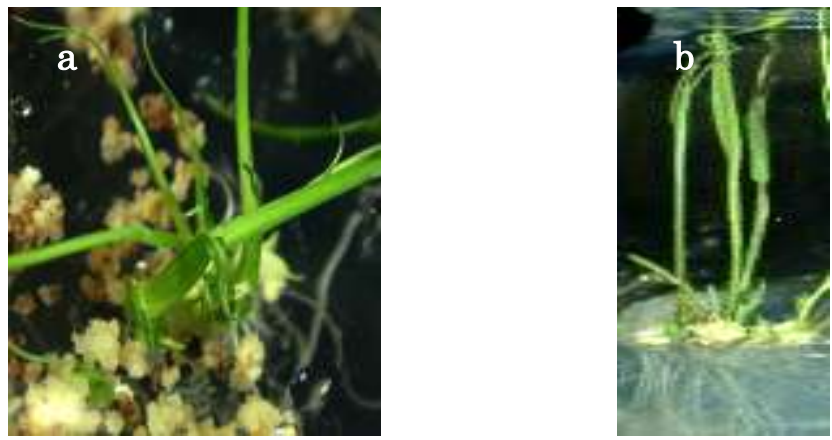

Fig. 2. (a) Regeneration (b) root formation of transgenic plants

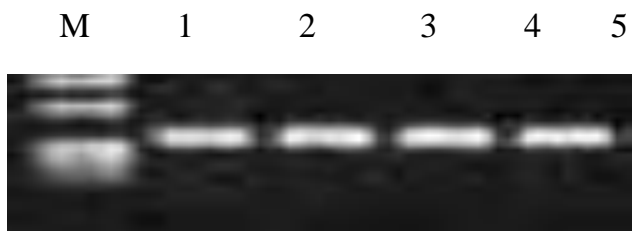

(a)

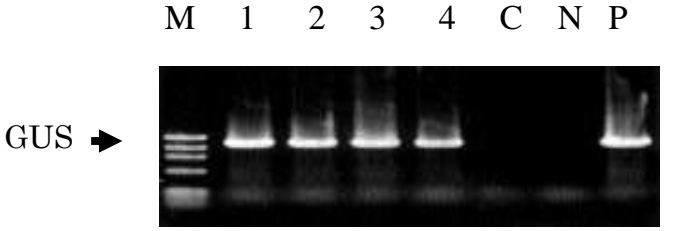

(b) PCR with short katE primer (1165 bp)

Fig.3. PCR amplification from the genomic DNA of transgenic Kasalath plants showing expected (a)GUS (between 310 and 610 bp), (b) katE fragment at 1165 bp. M, marker Hae III; C control; P positive control; $\mathrm{N}$ negative control.

\section{PCR analysis}

We have detected the insertion of katE and GUS gene by PCR from randomly selected regenerated $\mathrm{T}_{0}$ plants (Fig. $3 \mathrm{a}, \mathrm{b}$ ). This result shows that, transgene was proven to be integrated in all transformants examined. 

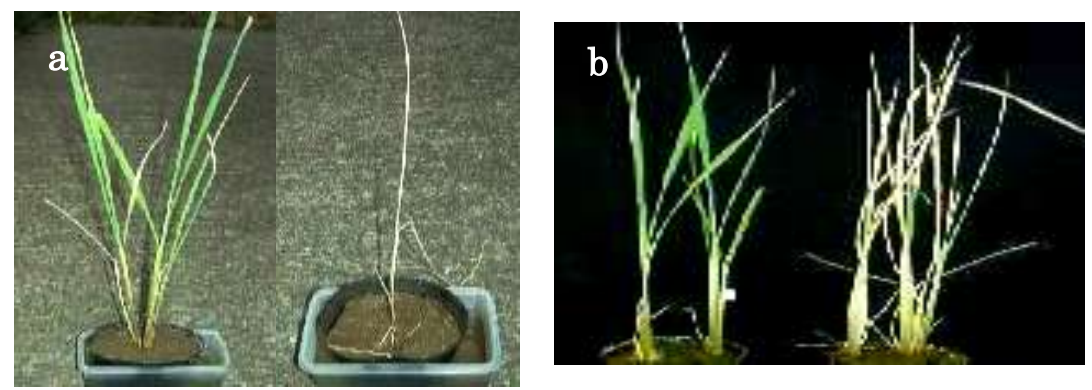

Fig. 4. (a) $\mathrm{T}_{0}$ plants under $150 \mathrm{mM} \mathrm{NaCl}$ concentration and photograph was taken 15 days after treatment (b) $\mathrm{T}_{1}-5$ plants, 10 days after salt water treatment at $250 \mathrm{mM} \mathrm{NaCl}$ solution

Table 1. Salt tolerance test of $T_{1}$ plants with $k a t E$ gene and $T_{0}$ plants with GUS gene.

\begin{tabular}{|c|c|c|c|c|c|c|c|c|c|c|}
\hline \multirow[t]{2}{*}{ In $50 \mathrm{mM}$ conc. } & \multicolumn{10}{|c|}{ Days after treatment } \\
\hline & 3 & 6 & 9 & 10 & 13 & 15 & 18 & 21 & 25 & 30 \\
\hline Non tr. Kasalath & +++ & +++ & +++ & +++ & +++ & +++ & +++ & ++ & ++ & + \\
\hline $\mathrm{T}_{1-\mathrm{L}-5}$ & +++ & +++ & +++ & +++ & +++ & +++ & +++ & +++ & +++ & ++ \\
\hline $\mathrm{T}_{1-\mathrm{L}} \mathrm{L}-11$ & +++ & +++ & +++ & +++ & +++ & +++ & +++ & ++ & ++ & ++ \\
\hline Kasalath by GUS* & +++ & +++ & +++ & +++ & +++ & +++ & +++ & ++ & + & + \\
\hline \multirow[t]{2}{*}{ In $100 \mathrm{mM}$ conc. } & \multicolumn{10}{|c|}{ Days after treatment } \\
\hline & 3 & 6 & 9 & 10 & 13 & 15 & 18 & 21 & 25 & 30 \\
\hline Non tr. Kasalath & +++ & +++ & ++ & ++ & + & - & - & - & - & \\
\hline $\mathrm{T}_{1-\mathrm{L}-5}$ & +++ & +++ & +++ & +++ & ++ & ++ & ++ & + & + & - \\
\hline $\mathrm{T}_{1-\mathrm{L}} \mathrm{L}-11$ & +++ & +++ & +++ & +++ & ++ & ++ & ++ & + & + & - \\
\hline Kasalath by GUS* & +++ & +++ & +++ & ++ & + & + & + & - & - & - \\
\hline \multirow[t]{2}{*}{ In $250 \mathrm{mM}$ conc. } & \multicolumn{10}{|c|}{ Days after treatment } \\
\hline & 3 & 6 & 9 & 10 & 13 & 15 & 18 & 21 & 25 & 30 \\
\hline Non tr. Kasalath & ++ & ++ & + & - & - & - & - & - & - & - \\
\hline $\mathrm{T}_{1-\mathrm{L}} \mathrm{L}-5$ & +++ & +++ & ++ & ++ & + & + & + & - & - & - \\
\hline $\mathrm{T}_{1-\mathrm{L}-11}$ & +++ & +++ & ++ & ++ & + & + & + & - & - & - \\
\hline Kasalath by GUS* & ++ & ++ & + & + & - & - & - & - & - & - \\
\hline
\end{tabular}

+++ , All leaves are green good condition; ++ , some portion of leaves are bleached; + , maximum portion of leaves are bleached; - almost dead and * transformed Kasalath with GUS gene but not with katE gene

We evaluated $\mathrm{T}_{0}$ transgenic and non transgenic plants for salt tolerance. At $100 \mathrm{mM}$ sodium chloride solution, 3 days aged plants survived until 15 days and control plants survived until 4 days. Same aged transgenic plants at $250 \mathrm{mM}$ concentration until 8 days where as control plants died at $2^{\text {nd }}$ days. $\mathrm{T}_{1}$ plants could grow for more than 14 days in the presence of $100 \mathrm{mM}$ sodium chloride solution and and in the presence of $250 \mathrm{mM}$ concentration plnts could survive up to 18 days (Fig. 4). On the contrary nontransgenic rice plants could not survive even in the presence of $50 \mathrm{mM}$ sodium chloride for more than 7 days and no seed were formed.

Many efforts have been made to produce salt tolerant rice plants by introduction of genes encoding proteins involved in protecting plants from environmental stress such as 
chloroplastic glutamine synthase (GS2), betain aldehyde dehydrogenase, calcium dependant protein kinase (CDPK) and others. Transformed rice plants with GS2 gene could survive for 2 weeks at $150 \mathrm{mM}$ sodium chloride (Hoshida et al. 2000). A gene encoding betaine aldehyde dehydrogenase, an enzyme involved in the synthesis of glycine betaine (CodA) produce a compatible solute regulating internal osmotic balance was introduced into rice genome and transgenic rice plants could survive 1 week at $150 \mathrm{mM}$ sodium chloride (Sakamoto et al. 1998) A gene encoding CDPK was introduced to the rice plant and the transformed rice plants could survive for 3 days at $200 \mathrm{mM}$ sodium chloride (Saijo et al. 2000). However, salt tolerance transgenic rice plants, which have been reported so far, have been able to grow in $150 \mathrm{mM}$ sodium chloride solution for 2 weeks at maximum. Transgenic rice plant with katE gene derived from $E$. coli as reported here, were able to form inflorescence in $100 \mathrm{mM}$ or lower concentration of $\mathrm{NaCl}$. They could survive for one month in $150 \mathrm{mM}$ and for 20 days in 200 and $250 \mathrm{mM} \mathrm{NaCl}$ concentration.

Salt tolerance of $\mathrm{T}_{1}$ plants from two lines seemed to be slightly weaker than that of $\mathrm{T}_{0}$ plants. They survived for 25 days in $100 \mathrm{mM}$ and for 18 days in $250 \mathrm{mM}$ concentration of $\mathrm{NaCl}$. So far reported here, this is one of the strongest salt tolerant Indica rice plants that could form inflorescence.

\section{Acknowledgment}

We are really grateful to Dr. T. Fujimura, Professor of Genetic Engineering, University of Tsukuba, Japan for his valuable discussion and technical advice. This research grant was supported by Japan Government Ministry of Education (Monbusho).

\section{REFERENCES}

Bohnert, H. J., D. Nelson and R. G. Jensen. 1995. Adaptations to environmental stress. Trends Biotechnol. 14:89-97.

James, D. J., Uratsu, S., Cheng, J., Negri, P., Viss, P. and Dandekar, A. M. 1993. Acetosyringon and osmoprotectants like betaine or praline synergistically enhance Agrobacterium mediated transformation of apple. Plant Cell Rep. 12: 559-563

Hashizume, F., T. Tsuchiya, M. Ugaki, Y. Niwa, N. Tachibana and Y. Kowyama. 1999. Efficient Agrobacterium mediated transformation and the usefulness of a synthetic GFP reporter gene in leading varieties of Japonica rice. Plant Biotech. 16(5): 397-401.

Hiei, Y., T. Komari and T. Kumashiro. 1994. Efficient Transformation of rice mediated by Aagrobacterium tumefaciens and sequence analysis of the boundaries of the T-DNA. The Plant Journal. 6:(2) $271-281$.

Hood, E. E., G. L. Helmer, R. T. Freiley and M. D. Chilton. 1986. The Hypervirulence of A. tumefaciens is encoded in a region of pTiBo542 outside of T- DNA. J. Bacteriol. Dec: 1291-1301.

Hoshida H, Y. Tanaka, T. Hibino, Y. Hayashi, A. Tanaka and T. Takabe. 2000. Enhanced tolerance to salt stress in transgenic rice that overexpresses chloroplast glutamine synthase, Plant Mol. Biol. 43: 103-111

Kaku, N., T. Hibino, Y. Meng, Y. Tanaka, E. Araki and T. Takabe. 2000. Effects of over expression of Escherichia coli kat $\mathrm{E}$ and bet genes on the tolerance for salt stresss in a fresh water Ccyanobacterium synechococcus sp. PCC 7942. Plant Sci. 159: 281- 288.

Ohta M, Y. Hayashi, A. Nakashima, A. Hamada, A. Tanaka, T. Nakamura and T. Hayakawa. 2002. Introduction of a $\mathrm{Na}^{+} / \mathrm{H}^{+}$antiporter gene from Atriplex gmelini confers salt tolerance to rice. FEBS Lett. 532: $279-282$.

Rashid, H., S. Yokoi, K. Toriyama and K. Hinata. 1996. Transgenic plant production mediated by Agrobacterium in indica rice. Plant Cell Rep. 15: 727-730.

Sakamoto, A, A. Murata and N. Murata. 1998. Metabolic engineering of rice leading to biosynthesis of glycinebetaine and tolerance to salt and cold, Plant Mol. Biol. 38: 1011-1019.

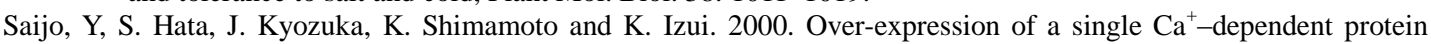
kinase confers both cold and salt/drought tolerance on rice plants, Plant J. 23: 319-327

Serrano, R. 1996. Salt tolerance in plants and microorganisms: toxicity targets and defense responses. Int. Rev Cytol. 165: $1-52$.

Toki, S. 1997. Rapid and efficient Aagrobacterium mediated transformation in rice. Plant Mol. Biol. 15(1): 16-21.

Van Wordragen, M. F., and Dons, H. I. M. 1992. Agrobacterium tumefaciens mediated transformation of recalcitrant crops. Plant Mol. Biol. Rep. 10: 12-36.

Vijayachandra, K, K. Palanichelvam and K. Veluthanbi. 1995. Rice scutellum induces Agrobacterium tumefaciens vir genes and T- strand generation. Plant Mol. Biol. 29: 125-133. 